\title{
Surgical Options for Failed Rotator Cuff Repair, except Arthroplasty: Review of Current Methods
}

\author{
Jangwoo Kim, Yunki Ryu, Sae Hoon Kim \\ Department of Orthopedic Surgery, Seoul National University Hospital, Seoul National University College of Medicine, Seoul, Korea
}

\begin{abstract}
Although the prevalence of rotator cuff tears is dependent on the size, $11 \%$ to $94 \%$ of patients experience retear or healing failure after rotator cuff repair. Treatment of patients with failed rotator cuff repair ranges widely, from conservative treatment to arthroplasty. This review article attempts to summarize the most recent and relevant surgical options for failed rotator cuff repair patients, and the outcomes of each treatment, except arthroplasty.
\end{abstract}

Keywords: Rotator cuff; Tendon transfers; Arthroscopic surgery; Subacromial impingement syndrome; Reconstructive surgical procedures

\section{INTRODUCTION}

Different studies have reported the rate of rotator cuff retear, in patients who underwent rotator cuff repair, to be between $11 \%$ and $94 \%$ [1-9]. Although the risk factors for retear are not clear, previous studies suggest older $[4,10]$, preoperative big tear size $[11,12]$, advanced degree of muscular atrophy [12], advanced degree of fatty infiltration [11,12], massive retraction of tendon [12,13], higher critical shoulder angle [14], lower acromiohumeral distance (AHD) [14], high tendon tension after repair, and inappropriate postoperative rehabilitation [12] as the major factors for failure of the rotator cuff repair. Management of patients with retear varies from conservative treatment to arthroplasty. This study attempts to summarize the reported results for surgical methods applied for treating rotator cuff retear, except arthroplasty.

\section{INDICATIONS}

There exists an uncertainty whether all patients with retear require revision surgery. Previous studies have shown that there is no correlation between the presence of retear and functional improvement $[1,15]$. Recently, however, several reports determined a significant correlation between integrity of the repaired tendon and functional improvement [16,17]. In addition, few studies have correlated increase in strength and recovery of function with cuff healing. Hence, the correlation with overall outcomes of the patient who underwent rotator cuff repair and cuff healing is still debatable $[2,18]$. It is therefore important to define the group of patients who require revision surgery, from among the failed rotator cuff repair patients. Previous studies suggest the following factors as having promising outcomes after reoperation: male [19], preoperative abduction above $90^{\circ}[19]$, preoperative forward flexion above

Received: December 9, 2019 Revised: December 30, 2019 Accepted: January 8, 2020

Correspondence to: Sae Hoon Kim

Department of Orthopedic Surgery, Seoul National University Hospital, 101 Daehak-ro, Jongno-gu, Seoul 03080, Korea

Tel: +82-2-2072-3930, Fax: +82-2-2072-3930, E-mail: drjacobkim@gmail.com, ORCID: https://orcid.org/0000-0002-6848-350X

Financial support: None.

Conflict of interest: None.

Copyright(C) 2020 Korean Shoulder and Elbow Society. All Rights Reserved.

This is an Open Access article distributed under the terms of the Creative Commons Attribution Non-Commercial License (http://creativecommons.org/licenses/by-nc/4.0/) which permits unrestricted non-commercial use, distribution, and reproduction in any medium, provided the original work is properly cited. 
$90^{\circ}[20]$, intact deltoid origin [20], good-quality rotator cuff tissue [20], only one prior procedure [20], increased AHD [21], the absence of glenohumeral arthritis [21], degenerative retear [21], and visual analog scale less than 5 [22]. However, some studies report that age and number of previous surgeries do not affect the outcome of revision surgery; hence, these two factors remain uncertain $[19,23]$. The authors of this review have determined the following factors for revision surgery: age $<65$ years, and confirmation of retear by sonography, computed tomography arthrography, or magnetic resonance imaging (MRI). Moreover, we also consider the patient's compliance, as well as their working and activity level.

\section{CLASSIFICATIONS}

The most commonly used classification of retear is the one suggested by Sugaya et al. [24] in 2005. In this study, the Sugaya et al's classification [24] divided the radiologic integrity of repaired cuff into five categories. Of these, type 4 and 5 are considered as retear in most papers. Type 4 is presence of a minor discontinuity in only one or two slices on both oblique coronal and sagittal images, suggesting a small full-thickness tear; type 5 is the presence of a major discontinuity observed in more than two slices on both oblique coronal and sagittal images, suggesting a medium or large full-thickness tear.

Among the several classification systems, the classification system proposed by Cho et al. [25] has important implications for predicting reparability. They divided the retear into two types, according to the presence of remnant tissue. The authors infer that type 2 retear, a medial row failure, has low reparability. In many studies, type 2 retear (or medial row failure) is significantly higher in rotator cuff repair using either the double row technique or the suture bridge technique [26].

Another classification system is based on the anatomical deficiency of the retear patient. The authors emphasize that the following six types of anatomical deficiencies should be considered in revision surgery: (1) failure of tendon healing, (2) poor tendon quality, (3) fatty infiltration/atrophy, (4) retear medial to the medial row of fixation, (5) bone defects in the greater tuberosity after anchor removal, or perianchor cyst formation, and (6) bony and tendinous insufficiency [27].

\section{SURGICAL PROCEDURES}

\section{Revision Repair}

Revision repair is the first surgical procedure considered in revision surgery of a retear. Lo and Burkhart [28] presented a technique and outcomes of an arthroscopic revision repair in a case se- ries of 14 patients. The authors emphasized a careful release technique when the torn tendon is difficult to identify due to medial retraction and fibrotic adhesion to adherent tissue during revision repair. In addition, tissues in non-anatomical areas are perplexing, but the authors claim that tendons can be dissected with careful manipulation. Compared to the preoperative state, patients in this study showed functional improvement. Several other studies have also reported alleviation of pain and functional improvement after revision repair. In 1992, Bigliani et al. [29] reported outcomes of 31 patients who underwent rotator cuff revision repair: 25 patients (81\%) reported pain relief, but 14 patients (45\%) had persistent weakness. Results of 20 patients who underwent rotator cuff revision repair were reported by $\mathrm{Ma}$ et al. [30]: 15 patients (75\%) reported pain relief, and the average forward flexion improved from $80^{\circ}$ preoperatively to $127^{\circ}$ postoperatively; 12 patients $(60 \%)$ reported no functional problems or minor limitations after surgery, and 11 patients (55\%) reported overall satisfaction with the surgical results.

However, a study comparing the results of revision repair with the results of primary repair did not show favorable outcomes of revision repair for all factors. Shamsudin et al. [17] retrospectively compared patients with primary repair and revision surgery. In revision surgery, the rerupture rate at 2-year follow-up was $40 \%$, which was significantly higher than that of primary repair $(21 \%)$. Moreover, revision surgery patients showed significantly inferior results than primary repair patients when considering postoperative pain, range of motion and strength. The authors reason that this could be because primary surgery inhibits microcirculation, and revision surgery is applied to repair already degenerated and weakened tendons.

Thorough subacromial decompression during revision repair is important in patients where acromiohumeral impingement is the primary cause of pain. Acromioplasty as a method of subacromial decompression was first described in 1995 by Rockwood et al. [31]. They performed acromioplasty in 50 irreparable cuff tear patients, and reported good outcomes in pain relief and restoration of active range of motion. Subacromial decompression is advantageous due to ease of execution by arthroscopy, and a recent report states that there is further pain reduction by additional tenotomy of the biceps long head [32]. Another method of subacromial decompression, tuberoplasty was first described in 2002 [33]. Arthroscopic tuberoplasty methods were first introduced in 2004 under the name "reversed arthroscopic subacromial decompression method" [34]. However, since acromioplasty and tuberoplasty surgery alone are unable to halt the progression of rotator cuff tear arthropathy and its associated osteoarthritis, their application in young retear patients is limit- 
ed and can be considered only for pain relief purposes [35].

Rotator cuff partial repair is a possible option for reducing pain and restoring function [36,37]. In 1994, the biomechanical "suspension bridge system" concept was introduced, and rotator cuff partial repair was first reported [37]. Since then, many authors have insisted that the rotator cuff cable can be restored by partial repair alone, with successful restoration of force-couple of the glenohumeral joint $[38,39]$. The following protocol is followed for partial repair. After sufficient tissue relaxation, chondroplasty is performed to medialize the footprint, by suturing the infraspinatus in the medialized footprint and suturing the long head of the biceps together. When performing partial repair, since complete cover of the superior portion is not possible, the anterior rotator cuff muscle group and the posterior rotator cuff muscle group must be firmly attached to the humeral head to ensure recovery of the force-couple [40]. Reports for partial repair outcomes are varied $[41,42]$. Most previous studies report pain relief and improved range of motion subsequent to partial repair, thereby supporting the theory that partial repair is appropriate for irreparable cuff tear patients. A recently published systematic review article on partial repair stated that there are methodological issues in the design of the study on rotator cuff partial repair published so far, such as selection bias, [43] and hence argued that it is too early to draw conclusions on the usefulness of this procedure.

There is another way to medialize the footprint for revision repair. Shifting the anatomic insertion of the rotator cuff to the medial side of the cartilage of the humeral head can be achieved if the torn tendon does not reduce to footprint even after sufficient intra-articular release of the tendon-capsular interface or extra-articular release of the tendon-bursal interface. There is a concern that the moment arm in abduction of medialized torn tendon may be shortened. However, previous biomechanical studies have reported no effect on the shoulder biomechanics during medialization of 3-10 mm [44,45]. Recently, Kim et al. [46] reported the results of medialization in 35 patients, wherein the range of motion and clinical scores were improved.

The double interval slide technique is another method applied to accomplish revision repair. In 2004, Lo and Burkhart [47] were the first to perform repair using the interval slide technique, in patients with massive and retracted cuff tears. Of the nine patients, six were subjected to single interval slide, and three patients underwent double interval slide repair. Single interval slide refers to the technique of repairing tendons after sufficient release of the rotator interval between supraspinatus and subscapularis to the coracoid process base. The double interval slide was introduced as a technique of releasing the base of the scapular spine between supraspinatus and infraspinatus, in addition to the single interval slide. $\mathrm{Pa}-$ tients included in this study showed improved strength and range of motion compared to preoperative values. However, some recent research has questioned the usefulness of interval slide technique. In 2013, Kim et al. [48] divided 41 patients with large-to-massive contracted rotator cuff tears into two groups: one group was subjected to partial repair with marginal convergence, whereas the second group underwent double interval slide repair. No functional difference was observed at 2-year follow-up in both groups, and retear rate was observed in 20 of the 22 patients who underwent a double interval slide (91\%), which was significantly higher than the partial repair with the marginal convergence group.

\section{Muscle Advancement}

It is well known that the original footprint cover is important for rotator cuff repair $[49,50]$. However, it is also known that retear increases significantly when excessive tension is applied to the repaired tendon for footprint cover [51]. Accordingly, many attempts have been made to reduce the tension of repaired cuff tendons. In 1965, Debeyre et al. [52] first introduced a technique to reduce tension during repair by elevating the supraspinatus from the supraspinatus fossa. Many authors have reported good results by following this method for tension-free repair $[49,53]$.

In the muscle advancement technique, an approximately $4-\mathrm{cm}$ incision is applied first at the medial side of the scapular spine, followed by detachment of the trapezius from the scapular spine. Supraspinatus and infraspinatus located under the detached trapezius are elevated from the scapula body and lateralized about $2 \mathrm{~cm}$ in order to cover the footprint of the humerus head (Figs. 1 and 2).

Recently, Yokoya et al. [49] published a comparative study of the muscle advancement technique. In this study, the authors performed a prospective comparative study of 47 chronic massive ro-
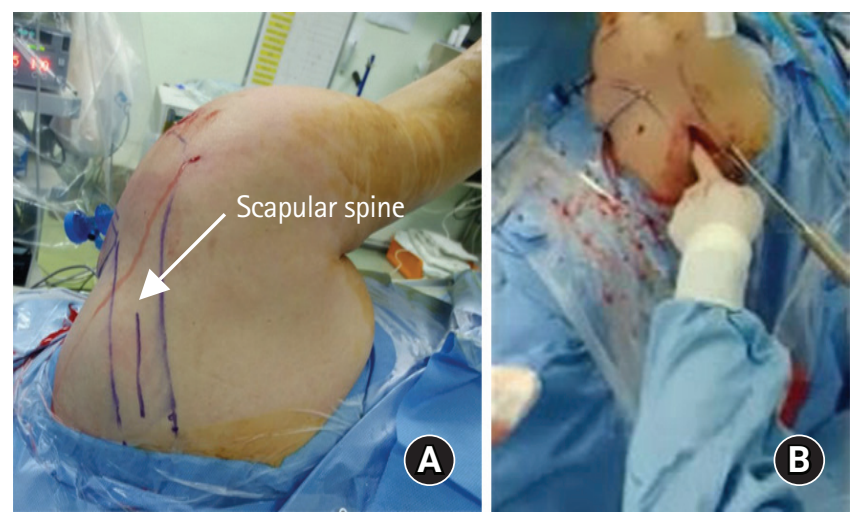

Fig. 1. (A) Surface anatomy for advancement. The part drawn in blue is the scapular spine. (B) Intraoperative procedure of advancement. About $5-\mathrm{cm}$ incision to detach trapezius and to elevate supraspinatus and infraspinatus from its fossa. 

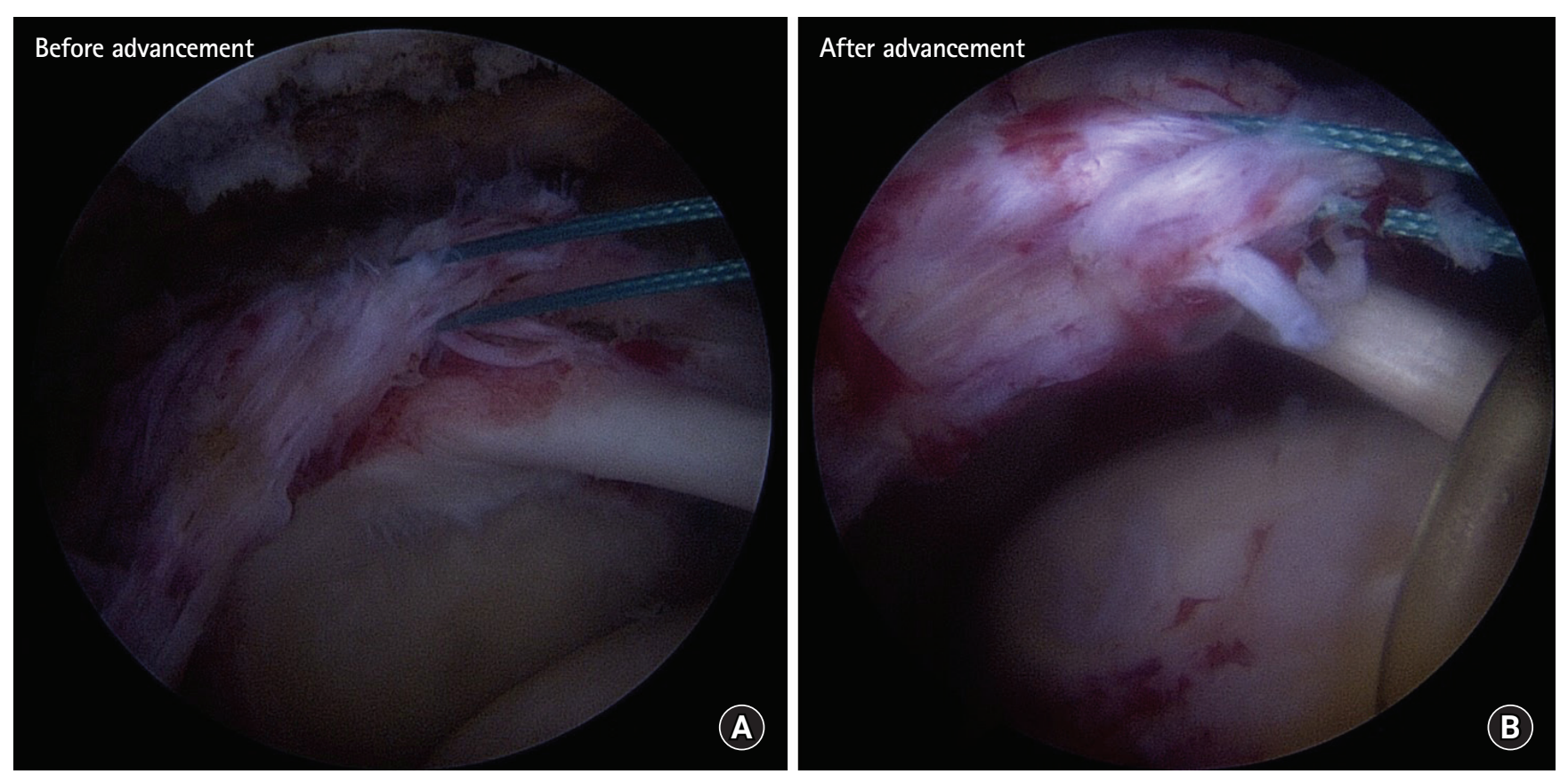

Fig. 2. (A) Arthroscopic views before (A) and after (B) muscle advancement technique.

tator cuff tear patients: 21 patients underwent transosseous equivalent (TOE) repair only, whereas 26 patients were subjected to TOE with muscle advancement. No difference was observed in the clinical score between groups, but the muscle advancement group showed significant improvement in abduction muscle strength and acromiohumeral interval compared to the TOE only group. Furthermore, the muscle advancement group reported lower retear rate, at $23.1 \%$ versus $52.4 \%$.

The muscle advancement technique has the advantage of covering the original footprint tension freely, but it is not an all-arthroscopic technique, and the excessive advancement during muscle advancement can lead to suprascapular nerve palsy [54]. Therefore, when performing muscle advancement technique, it is recommended to simultaneously cut the transverse scapular ligament arthroscopically for suprascapular nerve release introduced by Lafosse et al. [49,55].

\section{Patch Graft: Bridging Technique}

Patch graft interposition (bridging) techniques are applied for retracted, irreparable, and chronic rotator cuff tears in retear patients. The graft interposition technique was first introduced in 1978. In the first study, the authors used a freeze-dried allograft tendon to link the retracted rotator cuff with a greater tuberosity of humeral head, and reported good results such as pain relief [56]. However, another author group questioned the promising result of graft interposition using freeze-dried allograft tendon, and report- ed contradictory results. The authors reported that only two patients had functional improvement subsequent to the same procedure performed on seven patients included in the study [57]. Based on this research, numerous studies have been undertaken to overcome the problem of graft materials. Achilles tendon, tensor fascia latae, quadriceps femoris, and patellar tendon as allografts have been attempted, and the long head of biceps and fascia lata as autografts were also tried to link the cuff and footprint. New biomaterials such as polyester (Dacron), Gore-Tex, Teflon, and carbon fiber have been developed and are currently being actively researched [58-60]. Among the various trials, xenograft is practically not being used due to the significantly higher rerupture rate and severe inflammatory reaction [61].

There is only one randomized study of bridging techniques to date. In the study, 48 patients were divided into two groups. The control group underwent simple partial repair, and the treatment group underwent autograft bridging. Both showed significant functional improvement. However, the rerupture rate of infraspinatus (the rate of retear of the graft group) was significantly lower in the graft group (autograft vs. simple repair: $8.3 \%$ vs. $41.7 \%$, respectively). In addition, functional improvement in the rerupture group was lower than the non-retear group, and the author emphasized the usefulness of the patch graft [62]. A recently published meta-study argued that it was impulsive to conclude the usefulness of this procedure since there was only one high-level randomization study of the bridging technique mentioned above [63]. 


\section{Patch Graft: Augmentation}

The patch augmentation technique is considered when the cuff tendon of a retear reaches the medial margin of the footprint but is unable to cover the entire footprint (Fig. 3). Bond et al. [64] reported arthroscopic patch augmentation and its outcomes for the first time in 2008. They reported significant functional improvement and pain reduction in 16 massive tear patients, and follow-up MRI in 13 patients confirmed full recovery of the footprint. In 2015, Lenart et al. [65] reported the results of patients who underwent footprint augmentation using poly-l-lactide graft. This study reported significant functional improvement during the follow-up period, similar to the previous studies; however, retear was observed in $62 \%$ patients, thereby making it difficult to establish the stability of this procedure.

In 2017, a systematic review compared and presented bridging and augmentation techniques with patch graft. Based on the results of 12 studies included in this study, the overall healing rate of patch augmentation is $64 \%$ and the overall healing rate of bridging is $77.9 \%$. Furthermore, a significant alleviation was observed in the degree of pain in patients who underwent the bridging technique. The authors thereby concluded that bridging is a better option than augmentation in irreparable cuff patients [66].
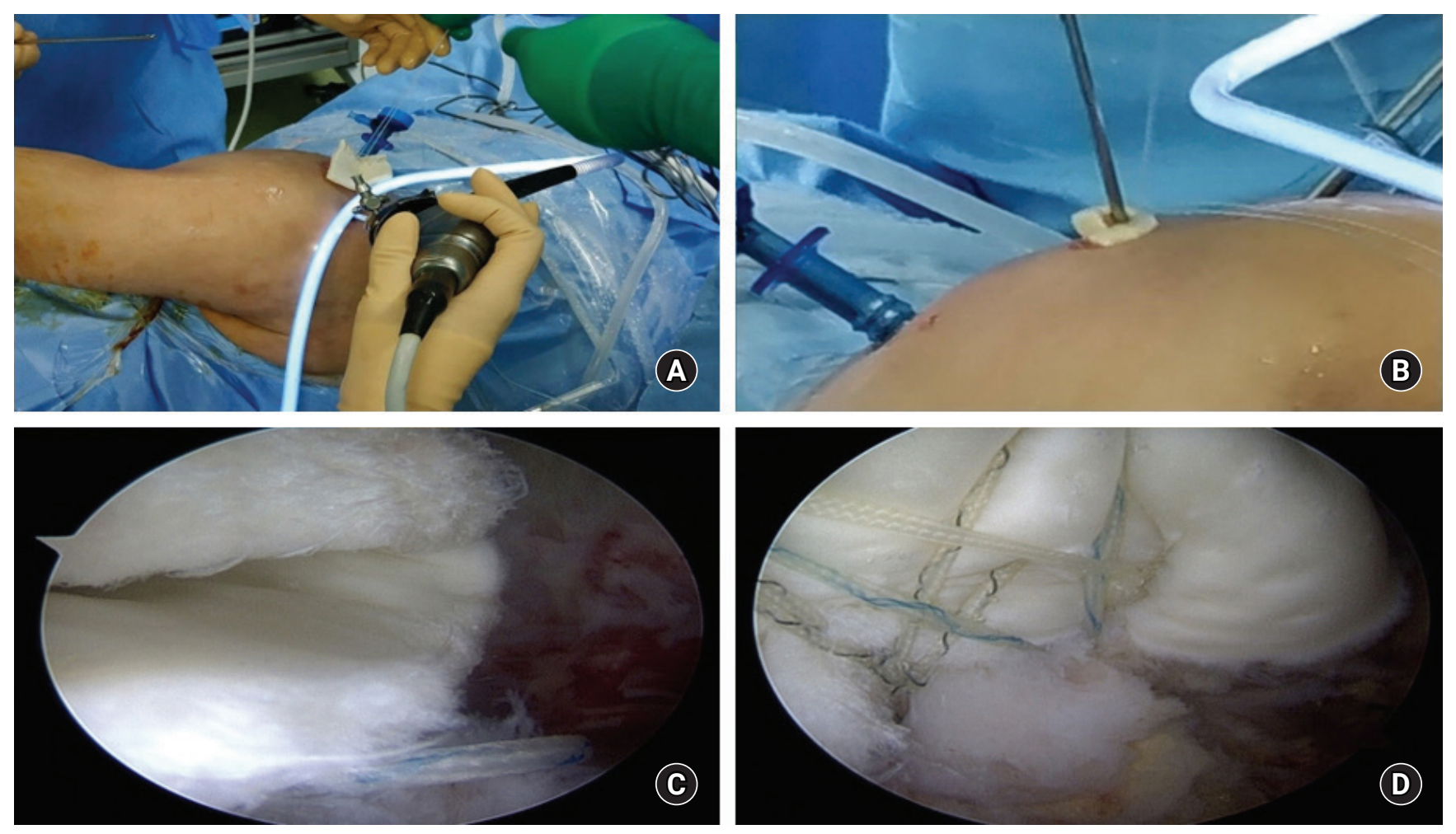

Fig. 3. (A, B) Photographs representing the procedure of arthroscopic allograft dermal patch augmentation. (C) Arthroscopic view entering allograft dermal patch. (D) Arthroscopic view after repair with patch augmentation. 
partial repair using interposition patch graft. The same authors also reported the results of superior capsular reconstruction clinical studies. The average follow-up period of 24 cases was 34 months. The forward elevation improved from $84^{\circ}$ to $148^{\circ}$ and the external rotation improved from $26^{\circ}$ to $40^{\circ}$. AHD increased from $4.6 \mathrm{~mm}$ to $8.7 \mathrm{~mm}$, and the American Shoulder and Elbow Surgeons scores were also significantly increased. Recently, the results of superior capsular reconstructions using synthetic patches (Arthrex Inc., Naples, FL, USA) or allograft skin tendons have been reported in consideration of morbidity of donor sites [59]. Moreover, there have been a number of favorable results for superior capsular reconstruction $[68,69]$. However, there is still doubt regarding the efficacy and long-term outcomes of superior capsular reconstruction; this technique has been reported in nearly $40 \%$ of reoperations in studies by authors other than those who developed superior capsular reconstruction [70,71]. There is also a debate on the difference in failure rate depending on whether the graft material is autograft or allograft. Of the various superior capsular reconstruction studies included in the systematic review published by Sochacki et al. [72] in 2019, the failure rate of the study using autograft is only $5 \%(5 / 100)$, but the failure rate of studies using allograft ranges from $3 \%(3 / 88)$ to $80 \%(4 / 5)$.

\section{Tendon Transfer: Latissimus Dorsi}

Tendon transfer is a good option for irreparable failed rotator cuff repair patients. Muscles commonly used for tendon transfer include latissimus dorsi (LD), pectoralis major (PM), and lower trapezius (LT) $[73,74]$. Since the LD transfer is intended to restore the posterior force-couple of the shoulder, LD transfer requires consideration in rupture of the rotator cuff, including posterior part of supraspinatus and infraspinatus and teres minor. In this procedure, the LD is detached from the lesser tuberosity of the humeral head (the original insertion site), and subsequently moved to the rear of the humerus and reattached to the greater tuberosity. This altered muscle vector changes $\mathrm{LD}$ orientation from internal rotator to external rotator. Authors who presented the results of LD transfer emphasized the abnormality of the subscapular muscle as a prerequisite for LD transfer, and warned that the outcomes of this technique may be inferior if the subscapular muscle is abnormal [75]. To predict a good prognosis for LD transfer, the authors do not recommended LD transfer in patients with eccentric humeral head position, patients with Hamada grade 4 or 5 glenohumeral osteoarthritis, and those with pseudoparalysis. In recent biomechanical experiments, LD transfer showed good results in the range of motion and stability of the glenohumeral joint; however, it was indicated that problems such as an "overcompensation phenomenon"
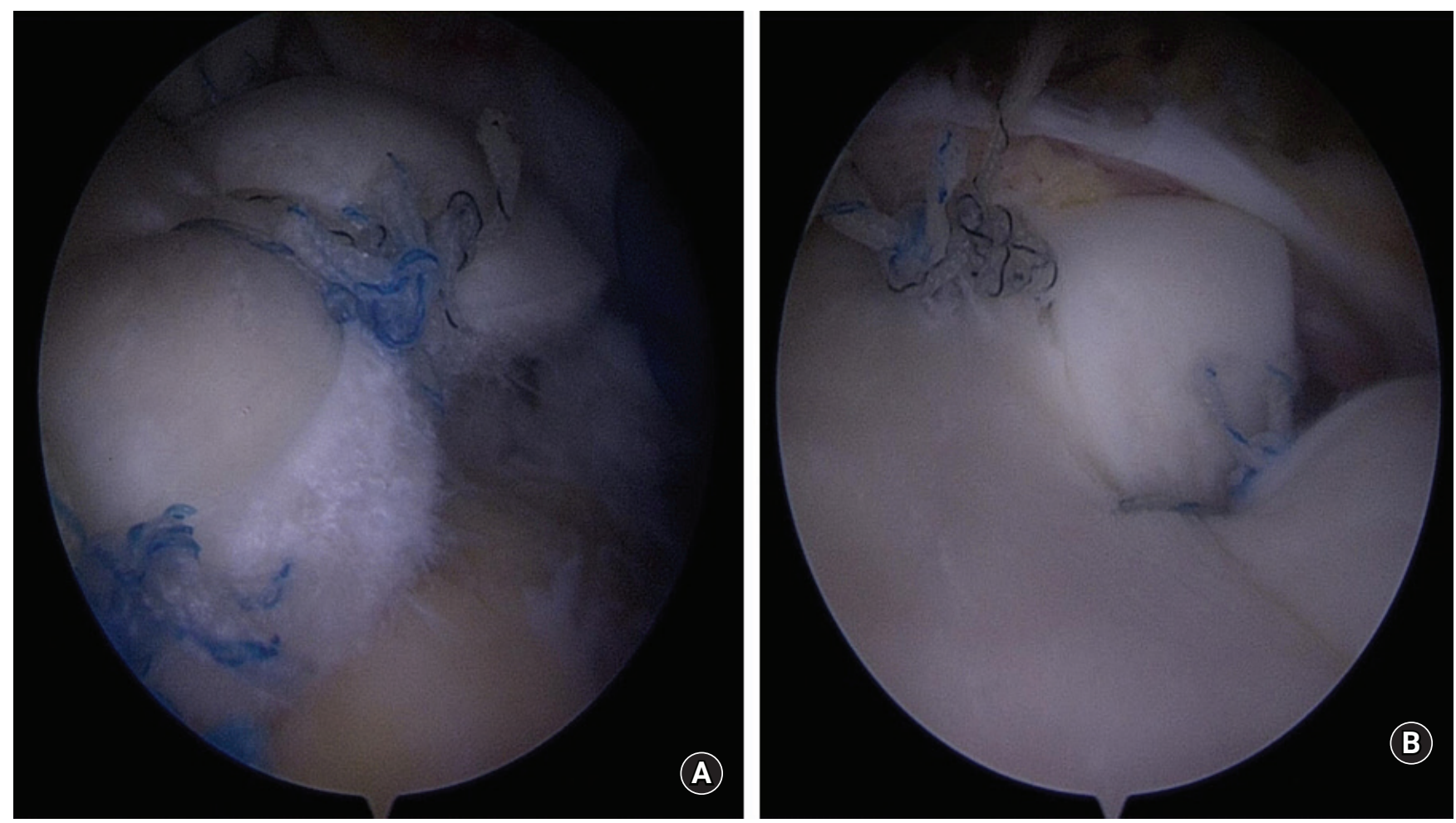

Fig. 4. Arthroscopic views of humeral footprint (A) and superior glenoid (B) after superior capsular reconstruction. 
can occur in the $60^{\circ}$ abduction position. An "overcompensation phenomenon" refers to an event wherein the contact pressure of the glenohumeral joint inevitably increases after LD transfer in patients with massive irreparable rotator cuff tears, whose force-couple disappears with simultaneous reduction in the glenohumeral joint contact peak pressure. This is the basis for negative results such as osteoarthritis, in long-term follow-ups [76]. Nevertheless, many authors report an improvement of the joint range of motion through LD transfer [77,78].

The recently introduced arthroscopic LD transfer has reported good results, and research on how the transferred LD actually works for active external rotation has continued [79]. Some authors performed electromyography on patients 1 year after LD transfer to determine if the actual LD was activated during external rotation. Indeed, by confirming the activation of the transferred $\mathrm{LD}$, they reasoned that LD transfer did not merely restore force coupling by maintaining shoulder stability but also recovers the external rotation strength [80]. However, another study disputed that LD transfer merely affects the centralizing of the glenohumeral joint resulting in a functional recovery, and not being converted to external rotator cuff. Therefore, the conclusion on this issue remains debatable [81].

In 2010, Valenti et al. [82] reported results of LD transfer as a revision surgery. Of the 25 patients included in the study, eight patients had revision surgery with LD transfer, and 17 patients had primary surgery with LD transfer. Both groups showed significant functional improvement and joint range of motion improvement compared to the preoperative condition, with no statistical difference between the groups. However, there was a significant difference in patient satisfaction: $84 \%$ of primary patients reported satisfaction, as against only $50 \%$ satisfied patients after revision surgery.

\section{Tendon Transfer: Pectoralis Major}

As opposed to LD transfer, PM transfer can be considered in patients with anterior muscle rupture of the rotator cuff surrounding the shoulder. This technique was first introduced in 1997 by Wirth and Rockwood [83] and many authors have subsequently reported good results $[84,85]$. Several surgical techniques for PM transfer have been introduced, such as transferring the entire PM, transferring the clavicular insertion only, or transferring the sternal side only. Surgical techniques can also be distinguished by the harvested path of the PM, which passes under or above the conjoined tendon and reattaches to the lesser tuberosity of the humeral head. Recently, some authors reported a comparison of the PM transfer paths, and argued that the biomechanical reattachment of PM under the conjoined tendon gave better outcomes [86]. PM transfer may be an available option in relatively young revision patients, but it is difficult to operate and has risks which include injury complications of the musculocutaneous nerve.

\section{Tendon Transfer: Lower Trapezius}

LT transfer was first introduced as a salvage procedure for patients with brachial plexus injury [87], and is now also performed in irreparable rotator cuff tear patients [88]. LT transfer is performed to restore the posterior force-couple of the shoulder, similar to the LD transfer described above, a prerequisite being an intact scapula muscle.

LT transfer has the following advantages over LD transfer. First, LD is an internal rotator, whereas LT is a muscle that is originally activated during external rotation of the shoulder, which makes it easier to rehabilitate the shoulder motion even after tendon transfer. It is also advantageous that the muscle contraction vector after transfer to greater tuberosity is almost similar to the original vector. However, since the tendon excursion is short, it is possible to attach the greater tuberosity only by bridging, such as autograft fascia lata or allograft Achilles tendon. Reddy et al. [89] recently published a study comparing the biomechanics of LT transfer and LD transfer using three-dimensional images. In this study, the LT showed overall better results than LD transfer due to stronger abduction moment arm.

\section{Subacromial Balloon Spacer}

Since 2012, some authors have reported on the use and results of biodegradable subacromial spacers in the treatment of irreparable rotator cuff tears [90-92]. This spacer is located between the acromion and humeral heads; when the deltoid muscle contracts, this spacer assists the humeral head to remain within the glenohumeral joint instead of upward displacement during shoulder forward flexion, abduction, and external rotation. These spacers are made of copolymer poly-L-lactide-co-e-caprolactone, allowing for survival of more than 12 months in the body, which helps restore the force-couple of the glenohumeral joint.

This balloon spacer can be inserted using a usual arthroscopic approach. After arthroscopic debridement, the gap between the acromion and the glenoid is measured; subsequently, a spacer of appropriate size is selected and inserted. It needs to be emphasized that this procedure can be used in the absence of injuries of the subscapularis, whereas patients with arthritis, having allergic reactions to external implants, and patients with existing infections are not indications.

Various authors have reported good results of this technique [93,94]. In 2019, Moon et al. [95] published a systematic review of seven previously published studies. Complications were reported in only six cases (3\%) of the 204 shoulders included in this study, 
and most of the patients showed satisfactory results during 2-3year follow-up. However, lack of high-level randomization studies on the use of balloon spacers requires further research.

\section{AUTHOR'S PREFERRED METHODS}

Surgery is primarily performed when the activity level and symptoms match, taking into account the age of the patient. If the patient condition requires surgery but does not correspond to the indication of reverse total shoulder arthroplasty, we first consider revision repair. If complete revision repair is not possible after sufficient tissue release, muscle advancement technique is considered. Superior capsular reconstruction is considered if the tendon quality is not good. Muscle transfer is considered as the last resort because it is at the expense of other muscles.

\section{CONCLUSION}

Surgical treatment of a failed rotator cuff repair patient is a challenging area. It is important to select the correct patients that require surgical intervention, and various surgical treatments need to be considered depending on the physical needs of the patient and condition of the retear or unhealed tendon.

\section{ORCID}

Yunki Ryu

Sae Hoon Kim
Jangwoo Kim https://orcid.org/0000-0001-9825-8541

https://orcid.org/0000-0003-4799-4797

https://orcid.org/0000-0002-6848-350X

\section{REFERENCES}

1. Galatz LM, Ball CM, Teefey SA, Middleton WD, Yamaguchi K. The outcome and repair integrity of completely arthroscopically repaired large and massive rotator cuff tears. J Bone Joint Surg Am 2004;86:219-24.

2. Harryman DT 2nd, Mack LA, Wang KY, Jackins SE, Richardson ML, Matsen FA 3rd. Repairs of the rotator cuff. Correlation of functional results with integrity of the cuff. J Bone Joint Surg Am 1991;73:982-9.

3. Lafosse L, Brozska R, Toussaint B, Gobezie R. The outcome and structural integrity of arthroscopic rotator cuff repair with use of the double-row suture anchor technique. J Bone Joint Surg Am 2007;89:1533-41.

4. Boileau P, Brassart N, Watkinson DJ, Carles M, Hatzidakis AM, Krishnan SG. Arthroscopic repair of full-thickness tears of the supraspinatus: does the tendon really heal? J Bone Joint Surg Am
2005;87:1229-40.

5. Frank JB, ElAttrache NS, Dines JS, Blackburn A, Crues J, Tibone JE. Repair site integrity after arthroscopic transosseous-equivalent suture-bridge rotator cuff repair. Am J Sports Med 2008; 36:1496-503.

6. Huijsmans PE, Pritchard MP, Berghs BM, van Rooyen KS, Wallace AL, de Beer JF. Arthroscopic rotator cuff repair with double-row fixation. J Bone Joint Surg Am 2007;89:1248-57.

7. Sugaya H, Maeda K, Matsuki K, Moriishi J. Repair integrity and functional outcome after arthroscopic double-row rotator cuff repair: a prospective outcome study. J Bone Joint Surg Am 2007;89:953-60.

8. Tashjian RZ, Hollins AM, Kim HM, et al. Factors affecting healing rates after arthroscopic double-row rotator cuff repair. Am J Sports Med 2010;38:2435-42.

9. Zumstein MA, Jost B, Hempel J, Hodler J, Gerber C. The clinical and structural long-term results of open repair of massive tears of the rotator cuff. J Bone Joint Surg Am 2008;90:2423-31.

10. Nho SJ, Brown BS, Lyman S, Adler RS, Altchek DW, MacGillivray JD. Prospective analysis of arthroscopic rotator cuff repair: prognostic factors affecting clinical and ultrasound outcome. J Shoulder Elbow Surg 2009;18:13-20.

11. Liem D, Lichtenberg S, Magosch P, Habermeyer P. Magnetic resonance imaging of arthroscopic supraspinatus tendon repair. J Bone Joint Surg Am 2007;89:1770-6.

12. Shin YK, Ryu KN, Park JS, Jin W, Park SY, Yoon YC. Predictive factors of retear in patients with repaired rotator cuff tear on shoulder MRI. AJR Am J Roentgenol 2018;210:134-41.

13. Meyer DC, Wieser K, Farshad M, Gerber C. Retraction of supraspinatus muscle and tendon as predictors of success of rotator cuff repair. Am J Sports Med 2012;40:2242-7.

14. Garcia GH, Liu JN, Degen RM, et al. Higher critical shoulder angle increases the risk of retear after rotator cuff repair. J Shoulder Elbow Surg 2017;26:241-5.

15. Nho SJ, Adler RS, Tomlinson DP, et al. Arthroscopic rotator cuff repair: prospective evaluation with sequential ultrasonography. Am J Sports Med 2009;37:1938-45.

16. Kim HM, Caldwell JM, Buza JA, et al. Factors affecting satisfaction and shoulder function in patients with a recurrent rotator cuff tear. J Bone Joint Surg Am 2014;96:106-12.

17. Shamsudin A, Lam PH, Peters K, Rubenis I, Hackett L, Murrell GA. Revision versus primary arthroscopic rotator cuff repair: a 2-year analysis of outcomes in 360 patients. Am J Sports Med 2015;43:557-64.

18. Gerber C, Fuchs B, Hodler J. The results of repair of massive tears of the rotator cuff. J Bone Joint Surg Am 2000;82:505-15.

19. Piasecki DP, Verma NN, Nho SJ, et al. Outcomes after ar- 
throscopic revision rotator cuff repair. Am J Sports Med 2010; 38:40-6.

20. Djurasovic M, Marra G, Arroyo JS, Pollock RG, Flatow EL, Bigliani LU. Revision rotator cuff repair: factors influencing results. J Bone Joint Surg Am 2001;83:1849-55.

21. Hartzler RU, Sperling JW, Schleck CD, Cofield RH. Clinical and radiographic factors influencing the results of revision rotator cuff repair. Int J Shoulder Surg 2013;7:41-5.

22. Neer CS. II SC. Reoperation for failed cuff repairs. In: Closed Meeting of the American Shoulder and Elbow Surgeons; 1987; Orlando, FL, USA.

23. Lädermann A, Denard PJ, Burkhart SS. Midterm outcome of arthroscopic revision repair of massive and nonmassive rotator cuff tears. Arthroscopy 2011;27:1620-7.

24. Sugaya H, Maeda K, Matsuki K, Moriishi J. Functional and structural outcome after arthroscopic full-thickness rotator cuff repair: single-row versus dual-row fixation. Arthroscopy 2005; 21:1307-16.

25. Cho NS, Yi JW, Lee BG, Rhee YG. Retear patterns after arthroscopic rotator cuff repair: single-row versus suture bridge technique. Am J Sports Med 2010;38:664-71.

26. Bedeir YH, Schumaier AP, Abu-Sheasha G, Grawe BM. Type 2 retear after arthroscopic single-row, double-row and suture bridge rotator cuff repair: a systematic review. Eur J Orthop Surg Traumatol 2019;29:373-82.

27. Lädermann A, Denard PJ, Burkhart SS. Management of failed rotator cuff repair: a systematic review. J ISAKOS 2016;1:32-7.

28. Lo IK, Burkhart SS. Arthroscopic revision of failed rotator cuff repairs: technique and results. Arthroscopy 2004;20:250-67.

29. Bigliani LU, Cordasco FA, McIlveen SJ, Musso ES. Operative treatment of failed repairs of the rotator cuff. J Bone Joint Surg Am 1992;74:1505-15.

30. Ma HL, Hung SC, Wang ST, Chen TH. The reoperation of failed rotator cuff repairs. J Chin Med Assoc 2003;66:96-102.

31. Rockwood CA Jr, Williams GR Jr, Burkhead WZ Jr. Débridement of degenerative, irreparable lesions of the rotator cuff. J Bone Joint Surg Am 1995;77:857-66.

32. Walch G, Edwards TB, Boulahia A, Nové-Josserand L, Neyton L, Szabo I. Arthroscopic tenotomy of the long head of the biceps in the treatment of rotator cuff tears: clinical and radiographic results of 307 cases. J Shoulder Elbow Surg 2005;14:238-46.

33. Fenlin JM Jr, Chase JM, Rushton SA, Frieman BG. Tuberoplasty: creation of an acromiohumeral articulation-a treatment option for massive, irreparable rotator cuff tears. J Shoulder Elbow Surg 2002;11:136-42.

34. Scheibel M, Lichtenberg S, Habermeyer P. Reversed arthroscopic subacromial decompression for massive rotator cuff tears. J
Shoulder Elbow Surg 2004;13:272-8.

35. Gerber C, Wirth SH, Farshad M. Treatment options for massive rotator cuff tears. J Shoulder Elbow Surg 2011;20:S20-9.

36. Berth A, Neumann W, Awiszus F, Pap G. Massive rotator cuff tears: functional outcome after debridement or arthroscopic partial repair. J Orthop Traumatol 2010;11:13-20.

37. Burkhart SS, Nottage WM, Ogilvie-Harris DJ, Kohn HS, Pachelli A. Partial repair of irreparable rotator cuff tears. Arthroscopy 1994;10:363-70.

38. Halder AM, O’Driscoll SW, Heers G, et al. Biomechanical comparison of effects of supraspinatus tendon detachments, tendon defects, and muscle retractions. J Bone Joint Surg Am 2002; 84:780-5.

39. Denard PJ, Koo SS, Murena L, Burkhart SS. Pseudoparalysis: the importance of rotator cable integrity. Orthopedics 2012;35: e1353-7.

40. Burkhart SS. Reconciling the paradox of rotator cuff repair versus debridement: a unified biomechanical rationale for the treatment of rotator cuff tears. Arthroscopy 1994;10:4-19.

41. Duralde XA, Bair B. Massive rotator cuff tears: the result of partial rotator cuff repair. J Shoulder Elbow Surg 2005;14:121-7.

42. Kim SJ, Lee IS, Kim SH, Lee WY, Chun YM. Arthroscopic partial repair of irreparable large to massive rotator cuff tears. Arthroscopy 2012;28:761-8.

43. Malahias MA, Kostretzis L, Chronopoulos E, Brilakis E, Avramidis G, Antonogiannakis E. Arthroscopic partial repair for massive rotator cuff tears: does it work? A systematic review. Sports Med Open 2019;5:13.

44. Liu J, Hughes RE, O’Driscoll SW, An KN. Biomechanical effect of medial advancement of the supraspinatus tendon: a study in cadavera. J Bone Joint Surg Am 1998;80:853-9.

45. Yamamoto N, Itoi E, Tuoheti Y, et al. Glenohumeral joint motion after medial shift of the attachment site of the supraspinatus tendon: a cadaveric study. J Shoulder Elbow Surg 2007;16:373-8.

46. Kim YK, Jung KH, Won JS, Cho SH. Medialized repair for retracted rotator cuff tears. J Shoulder Elbow Surg 2017;26:143240.

47. Lo IK, Burkhart SS. Arthroscopic repair of massive, contracted, immobile rotator cuff tears using single and double interval slides: technique and preliminary results. Arthroscopy 2004; 20:22-33.

48. Kim SJ, Kim SH, Lee SK, Seo JW, Chun YM. Arthroscopic repair of massive contracted rotator cuff tears: aggressive release with anterior and posterior interval slides do not improve cuff healing and integrity. J Bone Joint Surg Am 2013;95:1482-8.

49. Yokoya S, Nakamura Y, Harada Y, Ochi M, Adachi N. Outcomes of arthroscopic rotator cuff repair with muscle advancement for 
massive rotator cuff tears. J Shoulder Elbow Surg 2019;28:44552.

50. Yoo JC, Ahn JH, Koh KH, Lim KS. Rotator cuff integrity after arthroscopic repair for large tears with less-than-optimal footprint coverage. Arthroscopy 2009;25:1093-100.

51. Davidson PA, Rivenburgh DW. Rotator cuff repair tension as a determinant of functional outcome. J Shoulder Elbow Surg 2000;9:502-6.

52. Debeyre J, Patie D, Elmelik E. Repair of ruptures of the rotator cuff of the shoulder. J Bone Joint Surg Br 1965;47:36-42.

53. Haeri GB, Wiley AM. Advancement of the supraspinatus muscle in the repair of ruptures of the rotator cuff. J Bone Joint Surg Am 1981;63:232-8.

54. Warner JP, Krushell RJ, Masquelet A, Gerber C. Anatomy and relationships of the suprascapular nerve: anatomical constraints to mobilization of the supraspinatus and infraspinatus muscles in the management of massive rotator-cuff tears. J Bone Joint Surg Am 1992;74:36-45.

55. Lafosse L, Tomasi A, Corbett S, Baier G, Willems K, Gobezie R. Arthroscopic release of suprascapular nerve entrapment at the suprascapular notch: technique and preliminary results. Arthroscopy 2007;23:34-42.

56. Neviaser JS, Neviaser RJ, Neviaser TJ. The repair of chronic massive ruptures of the rotator cuff of the shoulder by use of a freezedried rotator cuff. J Bone Joint Surg Am 1978;60:681-4.

57. Nasca RJ. The use of freeze-dried allografts in the management of global rotator cuff tears. Clin Orthop Relat Res 1988;218-26.

58. Ozaki J, Fujimoto S, Masuhara K, Tamai S, Yoshimoto S. Reconstruction of chronic massive rotator cuff tears with synthetic materials. Clin Orthop Relat Res 1986;173-83.

59. Gupta AK, Hug K, Boggess B, Gavigan M, Toth AP. Massive or 2-tendon rotator cuff tears in active patients with minimal glenohumeral arthritis: clinical and radiographic outcomes of reconstruction using dermal tissue matrix xenograft. Am J Sports Med 2013;41:872-9.

60. Hohn EA, Gillette BP, Burns JP. Outcomes of arthroscopic revision rotator cuff repair with acellular human dermal matrix allograft augmentation. J Shoulder Elbow Surg 2018;27:816-23.

61. Ferguson DP, Lewington MR, Smith TD, Wong IH. Graft utilization in the augmentation of large-to-massive rotator cuff repairs: a systematic review. Am J Sports Med 2016;44:2984-92.

62. Mori D, Funakoshi N, Yamashita F. Arthroscopic surgery of irreparable large or massive rotator cuff tears with low-grade fatty degeneration of the infraspinatus: patch autograft procedure versus partial repair procedure. Arthroscopy 2013;29:1911-21.

63. Lewington MR, Ferguson DP, Smith TD, Burks R, Coady C, Wong IH. Graft utilization in the bridging reconstruction of ir- reparable rotator cuff tears: a systematic review. Am J Sports Med 2017;45:3149-57.

64. Bond JL, Dopirak RM, Higgins J, Burns J, Snyder SJ. Arthroscopic replacement of massive, irreparable rotator cuff tears using a GraftJacket allograft: technique and preliminary results. Arthroscopy 2008;24:403-9.

65. Lenart BA, Martens KA, Kearns KA, Gillespie RJ, Zoga AC, Williams GR. Treatment of massive and recurrent rotator cuff tears augmented with a poly-l-lactide graft, a preliminary study. J Shoulder Elbow Surg 2015;24:915-21.

66. Ono Y, Dávalos Herrera DA, Woodmass JM, Boorman RS, Thornton GM, Lo IK. Graft augmentation versus bridging for large to massive rotator cuff tears: a systematic review. Arthroscopy 2017;33:673-80.

67. Mihata T, Lee TQ, Watanabe C, et al. Clinical results of arthroscopic superior capsule reconstruction for irreparable rotator cuff tears. Arthroscopy 2013;29:459-70.

68. Mihata T, McGarry MH, Pirolo JM, Kinoshita M, Lee TQ. Superior capsule reconstruction to restore superior stability in irreparable rotator cuff tears: a biomechanical cadaveric study. Am J Sports Med 2012;40:2248-55.

69. Pennington WT, Bartz BA, Pauli JM, Walker CE, Schmidt W. Arthroscopic superior capsular reconstruction with acellular dermal allograft for the treatment of massive irreparable rotator cuff tears: short-term clinical outcomes and the radiographic parameter of superior capsular distance. Arthroscopy 2018; 34:1764-73.

70. Lee SJ, Min YK. Can inadequate acromiohumeral distance improvement and poor posterior remnant tissue be the predictive factors of re-tear? Preliminary outcomes of arthroscopic superior capsular reconstruction. Knee Surg Sports Traumatol Arthrosc 2018;26:2205-13.

71. Hirahara AM, Andersen WJ, Panero AJ. Superior capsular reconstruction: clinical outcomes after minimum 2-year follow-up. Am J Orthop (Belle Mead NJ) 2017;46:266-78.

72. Sochacki KR, McCulloch PC, Lintner DM, Harris JD. Superior capsular reconstruction for massive rotator cuff tear leads to significant improvement in range of motion and clinical outcomes: a systematic review. Arthroscopy 2019;35:1269-77.

73. Oh JH, Park MS, Rhee SM. Treatment strategy for irreparable rotator cuff tears. Clin Orthop Surg 2018;10:119-34.

74. Carver TJ, Kraeutler MJ, Smith JR, Bravman JT, McCarty EC. Nonarthroplasty surgical treatment options for massive, irreparable rotator cuff tears. Orthop J Sports Med 2018;6:2325967 118805385.

75. Werner CM, Zingg PO, Lie D, Jacob HA, Gerber C. The biomechanical role of the subscapularis in latissimus dorsi transfer for 
the treatment of irreparable rotator cuff tears. J Shoulder Elbow Surg 2006;15:736-42.

76. Oh JH, Tilan J, Chen YJ, Chung KC, McGarry MH, Lee TQ. Biomechanical effect of latissimus dorsi tendon transfer for irreparable massive cuff tear. J Shoulder Elbow Surg 2013;22:150-7.

77. Aoki M, Okamura K, Fukushima S, Takahashi T, Ogino T. Transfer of latissimus dorsi for irreparable rotator-cuff tears. J Bone Joint Surg Br 1996;78:761-6.

78. Gerber C, Maquieira G, Espinosa N. Latissimus dorsi transfer for the treatment of irreparable rotator cuff tears. J Bone Joint Surg Am 2006;88:113-20.

79. Grimberg J, Kany J, Valenti P, Amaravathi R, Ramalingam AT. Arthroscopic-assisted latissimus dorsi tendon transfer for irreparable posterosuperior cuff tears. Arthroscopy 2015;31:599-607.

80. Henseler JF, Nagels J, Nelissen RG, de Groot JH. Does the latissimus dorsi tendon transfer for massive rotator cuff tears remain active postoperatively and restore active external rotation? J Shoulder Elbow Surg 2014;23:553-60.

81. Irlenbusch U, Bernsdorf M, Born S, Gansen HK, Lorenz U. Electromyographic analysis of muscle function after latissimus dorsi tendon transfer. J Shoulder Elbow Surg 2008;17:492-9.

82. Valenti P, Kalouche I, Diaz LC, Kaouar A, Kilinc A. Results of latissimus dorsi tendon transfer in primary or salvage reconstruction of irreparable rotator cuff tears. Orthop Traumatol Surg Res 2010;96:133-8.

83. Wirth MA, Rockwood CA Jr. Operative treatment of irreparable rupture of the subscapularis. J Bone Joint Surg Am 1997;79:72231.

84. Galatz LM, Connor PM, Calfee RP, Hsu JC, Yamaguchi K. Pectoralis major transfer for anterior-superior subluxation in massive rotator cuff insufficiency. J Shoulder Elbow Surg 2003;12:1-5.

85. Lederer S, Auffarth A, Bogner R, et al. Magnetic resonance imaging-controlled results of the pectoralis major tendon transfer for irreparable anterosuperior rotator cuff tears performed with standard and modified fixation techniques. J Shoulder Elbow Surg 2011;20:1155-62.

86. Konrad GG, Sudkamp NP, Kreuz PC, Jolly JT, McMahon PJ,
Debski RE. Pectoralis major tendon transfers above or underneath the conjoint tendon in subscapularis-deficient shoulders: an in vitro biomechanical analysis. J Bone Joint Surg Am 2007; 89:2477-84.

87. Elhassan B, Bishop A, Shin A, Spinner R. Shoulder tendon transfer options for adult patients with brachial plexus injury. J Hand Surg Am 2010;35:1211-9.

88. Elhassan BT, Wagner ER, Werthel JD. Outcome of lower trapezius transfer to reconstruct massive irreparable posterior-superior rotator cuff tear. J Shoulder Elbow Surg 2016;25:1346-53.

89. Reddy A, Gulotta LV, Chen X, et al. Biomechanics of lower trapezius and latissimus dorsi transfers in rotator cuff-deficient shoulders. J Shoulder Elbow Surg 2019;28:1257-64.

90. Savarese E, Romeo R. New solution for massive, irreparable rotator cuff tears: the subacromial "biodegradable spacer". Arthrosc Tech 2012;1:e69-74.

91. Senekovic V, Poberaj B, Kovacic L, Mikek M, Adar E, Dekel A. Prospective clinical study of a novel biodegradable sub-acromial spacer in treatment of massive irreparable rotator cuff tears. Eur J Orthop Surg Traumatol 2013;23:311-6.

92. Senekovic V, Poberaj B, Kovacic L, et al. The biodegradable spacer as a novel treatment modality for massive rotator cuff tears: a prospective study with 5-year follow-up. Arch Orthop Trauma Surg 2017;137:95-103.

93. Deranlot J, Herisson O, Nourissat G, et al. Arthroscopic subacromial spacer implantation in patients with massive irreparable rotator cuff tears: clinical and radiographic results of 39 retrospectives cases. Arthroscopy 2017;33:1639-44.

94. Malahias MA, Brilakis E, Avramidis G, Antonogiannakis E. Satisfactory mid-term outcome of subacromial balloon spacer for the treatment of irreparable rotator cuff tears. Knee Surg Sports Traumatol Arthrosc 2019;27:3890-6.

95. Moon AS, Patel HA, Ithurburn MP, Brabston EW, Ponce BA, Momaya AM. Subacromial spacer implantation for the treatment of massive irreparable rotator cuff tears: a systematic review. Arthroscopy 2019;35:607-14. 